\title{
Metal-Free Catalysis of Persulfate Activation and Organic-Pollutant Degradation by Nitrogen-Doped Graphene and Aminated Graphene
}

\author{
Hao Chen ${ }^{1}$ and Kenneth C. Carroll ${ }^{1 *}$ \\ ${ }^{1}$ Department of Plant and Environmental Sciences, New Mexico State University, MSC 3Q P.O. \\ Box 30003, Las Cruces, N.M. 88003-8003, United States
}

Submitted for Review to:

Environmental Pollution

February 13, 2016

Revised: March 29, 2016

*Corresponding author (kccarr@nmsu.edu)

Chen-Carroll-PersulfateGraphene-Revised-Clean.doc

(C) 2016. This manuscript version is made available under the Elsevier user license http://www.elsevier.com/open-access/userlicense/1.0/ 


\section{ABSTRACT:}

We evaluated three types of functionalized, graphene-based materials for activating persulfate (PS) and removing (i.e., sorption and oxidation) sulfamethoxazole (SMX) as a model emerging contaminant. Although advanced oxidative water treatment requires PS activation, activation requires energy or chemical inputs, and toxic substances are contained in many catalysts.

Graphene-based materials were examined herein as an alternative to metal-based catalysts. Results show that nitrogen-doped graphene (N-GP) and aminated graphene $\left(\mathrm{NH}_{2}-\mathrm{GP}\right)$ can effectively activate PS. Overall, PS activation by graphene oxide was not observed in this study. N-GP $\left(50 \mathrm{mg} \mathrm{L}^{-1}\right)$ can rapidly activate PS $(1 \mathrm{mM})$ to remove $>99.9 \%$ SMX within 3 hours, and $\mathrm{NH}_{2}$-GP $\left(50 \mathrm{mg} \mathrm{L}^{-1}\right)$ activated PS $(1 \mathrm{mM})$ can also remove 50\% SMX within 10 hours. SMX sorption and total removal was greater for N-GP, which suggests oxidation was enhanced by increasing proximity to PS activation sites. Increasing $\mathrm{pH}$ enhanced the N-GP catalytic ability, and $>99.9 \%$ SMX removal time decreased from 3 hours to 1 hour when pH increased from 3 to 9. However, the PS catalytic ability was inhibited at $\mathrm{pH} 9$ for $\mathrm{NH}_{2}-\mathrm{GP}$. Increases in ionic strength (100 $\mathrm{mM} \mathrm{NaCl}$ or $\left.\mathrm{Na}_{2} \mathrm{SO}_{4}\right)$ and addition of radical scavengers (500 mM ethanol) both had negligible impacts on SMX removal. With bicarbonate addition $(100 \mathrm{mM})$, while the catalytic ability of $\mathrm{N}-\mathrm{GP}$ remained unaltered, $\mathrm{NH}_{2}-\mathrm{GP}$ catalytic ability was inhibited completely. Humic acid (250 $\mathrm{mg} \mathrm{L}^{-1}$ ) was partially effective in inhibiting SMX removal in both N-GP and $\mathrm{NH}_{2}-\mathrm{GP}$ systems. These results have implications for elucidating oxidant catalysis mechanisms, and they quantify the ability of functionalization of graphene with hetero-atom doping to effectively catalyze PS for water treatment of organic pollutants including emerging contaminants. 
Capsule Abstract: Nitrogen-doped and aminated graphene persulfate activation and sulfamethoxazole decay didn't require chemical or energy input.

Keywords: Persulfate; graphene; sulfamethoxazole; nitrogen doped graphene; aminated graphene; emerging contaminant 


\section{INTRODUCTION}

Interest in advanced oxidation for in situ chemical oxidation (ISCO) has increased due to the need to degrade a wide and growing range of organic pollutants detected in subsurface especially emerging contaminants (e.g., pharmaceuticals, personal care products, pesticides, and endocrine disrupting compounds) (Thiele-Bruhn 2003 ; Barnes, Christenson et al. 2004). Persulfate (PS), is low cost, chemically stable, and convenient to store and transport (Hussain, Green et al. 2013). Activated persulfate is an increasingly popular oxidant for ISCO based on the advantages of persulfate over other regularly used oxidants such as ozone, $\mathrm{H}_{2} \mathrm{O}_{2}$, and permanganate (Watts and Teel 2006). Due to the symmetric structure of PS molecules and reasonably high bonding energy, PS itself exhibits a relatively low oxidation potential (Kolthoff and Miller 1951). Therefore, external activation is typically needed for PS oxidation of organic contaminants (Cuypers, Grotenhuis et al. 2000, Tsitonaki, Petri et al. 2010). After activation, PS then becomes a strong oxidant (up to $\mathrm{E}^{\circ}=2.05 \mathrm{~V}$ ), and therefore, interest is significant for activating PS in water treatment to degrade emerging contaminants under a broad spectrum of environmental conditions.

Both physical activation like UV irradiation and heating (Kronholm, Metsälä et al. 2001, Yang, Pignatello et al. 2014) and chemical activation such as bases, phenols, and quinones have been reported to be effective for PS activation (Furman, Teel et al. 2010, Ahmad, Teel et al. 2013, Fang, Gao et al. 2013). The PS activation may occur either through generation of free radicals or by nonracial processes (Zhang, Zhu et al. 2013). Recently, electrochemical methods or electron donors (zerovalent iron or ferrous ion (II)) also have been used for PS activation (Drzewicz, Perez-Estrada et al. 2012, Ahn, Peterson et al. 2013, Cai, Zhang et al. 2014, Chaplin 2014, 
Zhong, Brusseau et al. 2015). The focus has been on efficient and low-cost transition metal catalysis including $\mathrm{Cu}, \mathrm{Co}$, and others (Anipsitakis and Dionysiou 2003; Anipsitakis and Dionysiou 2004, Chaplin 2014). The release of toxic metal catalysts during treatment is a significant concern (Chaplin 2014). All of the above approaches require energy or chemical inputs, and they may release toxic substances into the water (Tsitonaki, Petri et al. 2010).

Carboncatalysis is now emerging for various reactions, and several of these metal-free catalysts may be suitable for PS. Multiwalled carbon nanotubes (CNTs) have been demonstrated to be effective for PS activation for phenol oxidation (Lee, Lee et al. 2015, Wang, Qin et al. 2015), and Sun and co-workers reported that reduced graphene oxide can activate peroxymonosulfate to generate radicals (Sun, Liu et al. 2012). Nitrogen-doped carbon nanomaterials have also been used to effectively catalyze PS through radical generation (Duan, Ao et al. 2015). The $\mathrm{SP}^{2}$ covalent carbon network and oxygen functional groups at the defective edges of carbonaceous materials have been suggested to support a redox cycle for electron transfer to aqueous PS at the solid-liquid interface, which activates PS (Zhao, Nakamura et al. 2013, Lee, Lee et al. 2015). Although carboncatalysis shows promise for PS activation, a thorough understanding of the activation process and organic-pollutant treatment evaluation is still lacking especially for functionalized graphene-based materials.

Graphene-based materials with various types of functionalization are available, and they have unique properties including charge transportation, electrical conductivity, mechanical strength, and porosity (Kuila, Bose et al. 2012). This study examined the variability and potential of functionalized graphene-based materials as carboncatalysis tools for PS activation. Graphene- 
based materials, including nitrogen-doped graphene (N-GP), aminated graphene $\left(\mathrm{NH}_{2}-\mathrm{GP}\right)$, and graphene oxides (GO), and model emerging contaminant sulfamethoxazole (SMX) were used in batch experiments under various conditions to elucidate the possible pathway for PS activation. SMX was used as the model contaminant to test the pollution degradation ability of graphenebased activation of PS, since SMX is widely used in health care and agricultural industries for the treatment and prevention of human and animal diseases and is an example emerging contaminant commonly found in various environments. (Baran, Adamek et al. 2011) Our objectives were to: 1) compare the functionalization impact on PS activation; 2) understand the effects of solution $\mathrm{pH}$ and ionic strength on PS activation and SMX removal; 3) examine radical scavenger (ethanol) effects on PS activation and SMX removal; 4) evaluate the effects of variations in aquatic chemistry (i.e., $\mathrm{pH}$, bicarbonate, and humic acid) on PS activation and SMX removal in graphene and PS systems.

\section{MATERIAL AND METHODS}

\subsection{Materials}

Sulfamethoxazole (SMX) (ACS 723-46-6) was purchased from Applichem (Darmstadt, Germany) with $\log K_{\mathrm{ow}}=0.79$ and the chemical structure shown in Table S1 (Lee, Lee et al. 2013). SMX stock solution was prepared in distilled-deionized nanopure (Series 550, Barnstead Thermolyne Corp., Dubuque, Indiana) (hereafter termed DI) water, and stored at $4^{\circ} \mathrm{C}$ in dark prior to use. N-GP, $\mathrm{NH}_{2}$-GP and GO were all purchased from ACS materials (Medford, MA); their component and structure properties are shown in Table S2. The following chemicals were 
used as received: $\mathrm{Na}_{2} \mathrm{~S}_{2} \mathrm{O}_{8}\left(98 \%\right.$, Alfa Aesar), $\mathrm{Na}_{2} \mathrm{~S}_{2} \mathrm{O}_{3}$ (99\%, Fisher), $\mathrm{NaHCO}_{3}$ (99\%, Sigma), $\mathrm{NaCl}$ (98\%, Sigma-Aldrich), $\mathrm{KI}$ (99\%, Fisher), $\mathrm{Na}_{2} \mathrm{SO}_{4}$ (99\%, Sigma-Aldrich), humic acid (99\%, Sigma), ethanol (95\%, Aldrich), $\mathrm{NaOH}$ (99\%, Fisher), and $\mathrm{HCl}$ (99\%, Aldrich). Stock solutions of all chemicals were prepared in DI water, and prior to each experiment, specific aliquots were transferred to the reactor vessel to obtain the concentrations reported.

\subsection{Experiment Procedures}

Batch, kinetics experiments were performed in 50-mL reactor vessels (glass centrifuge tubes) with SMX solution $\left(5 \mathrm{mg} \mathrm{L}^{-1}\right)$, graphene-based catalyst $\left(50 \mathrm{mg} \mathrm{L}^{-1}\right)$, and PS $(1 \mathrm{mM})$ to start the reaction. Sorption experiments (i.e., oxidation controls) were conducted by SMX in graphene suspension without PS, and variable aqueous chemistry experiments were compared to experiments conducted in DI water. Where required, the initial $\mathrm{pH}$ was adjusted by addition of appropriate amounts of $\mathrm{HCl}(0.1 \mathrm{M})$ or $\mathrm{NaOH}(0.1 \mathrm{M})$. During the investigations of the effects of $\mathrm{NaCl}$ and $\mathrm{Na}_{2} \mathrm{SO}_{4}, 100 \mathrm{mM}$ of salt were added to each individual reactor before addition of PS.

Either $500 \mathrm{mM}$ ethanol, $100 \mathrm{mM} \mathrm{NaHCO}_{3}$, or $250 \mathrm{mg} \mathrm{L}^{-1}$ humic acid were added individually to additional experiment reactor solutions before addition of PS to test the potential effects of adding oxidant consumers. Samples were mixed by shaking at $50 \mathrm{rpm}$ then removed at several different time intervals, and were filtered through $0.22 \mu \mathrm{m}$ syringe filters. $10 \mathrm{mM}$ sodium thiosulfate, as persulfate quenching agent (which was confirmed to have no analysis interference), was added in 1:1 volume ratio to each sample. Sorption and overall removal (i.e., sorption and degradation) were quantified by loss from aqueous solution. Unless specifically 
noted, all the experiments were carried out at ambient temperature of $20 \pm 2{ }^{\circ} \mathrm{C}$, and were exposed to air. All the experimental samples were performed in duplicate or triplicate, and the average and standard deviation values have been reported.

\subsection{Analysis Methods}

The analysis of aqueous SMX was carried out using a HPLC (Waters 2695, Milford, MA) equipped with a Nova-Pak C18 column $(150 \mathrm{~mm} \times 3.9 \mathrm{~mm}$, Waters Millipore $)$. The mobile phase consisted of acetonitrile and $0.5 \%$ phosphoric acid at a ratio of 15:85. A UV detector (Waters) was used to detect SMX at the wavelength $268 \mathrm{~nm}$. The SMX detection limit was 0.5 $\mathrm{mg} \mathrm{L}{ }^{-1}$, and the linear range was $0.5-50 \mathrm{mg} \mathrm{L}^{-1}$ with correlation coefficients $\left(\mathrm{R}^{2}\right)>0.99$.

A modified iodide spectrophotometry method was used to determine aqueous persulfate $\left(\mathrm{S}_{2} \mathrm{O}_{8}{ }^{2-}\right)$ (Liang, Huang et al. 2008). Briefly, KI salt was dissolved in a $5 \mathrm{~g} \mathrm{~L}^{-1} \mathrm{NaHCO}_{3}$ solution to the concentration of $100 \mathrm{~g} \mathrm{~L}^{-1}$. Samples were mixed with the $\mathrm{KI}-\mathrm{NaHCO}_{3}$ solution at a ratio of 1:19 (v:v). Absorptivity of the solution was measured after a 20 minute holding time with a UV spectrophotometer (Fisher, Loveland, CO) at a wavelength of $352 \mathrm{~nm}$. Samples were also analyzed for sulfate using a Spectronic 20 spectrophotometer with flow through cell analysis following the EPA 375.4 method. The $\mathrm{pH}$ of the samples was measured with a calibrated $\mathrm{pH}$ meter (Accument, Fisher Scientific, GA). 


\section{RESULTS AND DISCUSSION}

\subsection{Decomposition of Persulfate}

Normalized PS concentration versus $\sim 15$ day temporal profiles for experiments conducted identically except for difference in the graphene-based material used are shown in Fig. 1. For N-GP with PS and $\mathrm{NH}_{2}-\mathrm{GP}$ with PS systems, the decrease of PS concentration indicated decomposition of PS in each system. Measured sulfate concentrations increased as PS concentrations decreased confirming PS activation. However, PS concentration remained stable in the GO system as well as the activator-free, control experiments (Fig.1), indicating GO, without nitrogen-based functionalization, had negligible interaction with PS in DI water.

In both $\mathrm{N}-\mathrm{GP}$ with PS and $\mathrm{NH}_{2}-\mathrm{GP}$ with PS systems, the $\mathrm{pH}$ decreased from initial $\mathrm{pH}$ 6.0 to $\sim \mathrm{pH} 3.0$ after 15 days. The decreased $\mathrm{pH}$ can be explained by the consumption of hydroxyl ions and generation of sulfate acid during PS decomposition (Furman, Teel et al. 2010).

\subsection{Removal of SMX}

Without graphene-based activation in the control, SMX degradation was negligible over the time-scales investigated (Table S3). With different graphene-based materials, the ability of PS to remove SMX varied substantially (Fig. 2). Both N-GP and $\mathrm{NH}_{2}-\mathrm{GP}$ effectively activated

PS resulting in SMX removal: SMX removal in N-GP with PS system reached $>99.9 \%$ removal within 3 hours; SMX concentration decreased more slowly in $\mathrm{NH}_{2}-\mathrm{GP}$ with PS system, but still reached $50 \%$ SMX removal within $\sim 10$ hours. In comparison for the GO-PS system, the SMX 
concentration remained relatively stable (Fig. 2), and the PS concentration remained essentially unchanged from the initial (Fig.1).

N-GP was the most effective graphene-based material, examined herein, for catalyzing PS and rapidly reaching >99.9\% SMX removal (as noted above), and achieving 10\% PS decay in 3 hours (Fig. $1 \& 2$ ). This rapid PS catalytic ability of N-GP can likely be attributed to the electron-rich, nitrogen-functional surface species, such as pyridinic-N, quaternary- $\mathrm{N}$, and quaternary N (Wang, Maiyalagan et al. 2012). Graphitic nitrogen doping and nitrogen atoms at graphene defective sites conjugated with the lone-pair electrons can activate graphene $\mathrm{SP}^{2}$ carbon with free-flowing $\pi$-electrons for PS activation (Sun, Wang et al. 2013). Additionally, NGP also exhibited the highest SMX sorption ability, which suggests that the nitrogen-doping structural groups likely act as the active sites for both adsorption and oxidation catalysis. The $\mathrm{Kd}$ was $72 \mathrm{~L} \mathrm{Kg}^{-1}$ after $60 \mathrm{~min}$ for SMX on N-GP, and a Kd of $20 \mathrm{~L} \mathrm{Kg}^{-1}$ was obtained after $60 \mathrm{~min}$ for $\mathrm{NH}_{2}$ - $\mathrm{GP}$ (see figures in ionic strength section below), where the $\mathrm{Kd}\left(\mathrm{L} \mathrm{Kg}^{-1}\right)=$ Sorbed Concentration $\left(\mathrm{mg} \mathrm{Kg}^{-1}\right) /$ Dissolved Concentration $\left(\mathrm{mg} \mathrm{L}^{-1}\right)$. Thus, enhanced sorption can facilitate SMX enrichment onto N-GP surface, which can increase proximity to PS activation sites and further accelerate SMX oxidative decomposition by PS (Wang, Qin et al. 2015).

Compared to N-GP, $\mathrm{NH}_{2}$-GP was less effective for PS activation, after 2 hours only $30 \%$ SMX removal with 30\% PS consumption. Thus, the SMX removal rate within the $\mathrm{NH}_{2}$-GP suspension was significantly slower than that of the removal rate within the N-GP suspension. Exponential regression was used to estimate SMX pseudo-first order rate coefficients, which were 1.95 hour $^{-1}$ for the $\mathrm{N}-\mathrm{GP}$ system and 0.05 hour $^{-1}$ for the $\mathrm{NH}_{2}$-GP system (Fig. S1). However, 
pseudo-first order regression analyses did not reproduce the observed trends for all experiments, which suggests the potential for non-first order kinetics. This was not unexpected for the series of reactions that include PS activation and SMX oxidation. The decreased SMX transformation rate within the $\mathrm{NH}_{2}$-GP system was unexpected. Prior work has found that aromatic amines can react with PS (Sepulveda and Binner 2001). However, similar to observations during Fenton reactions, aromatic amines can also be transformed during PS oxidation (Jiang, Zhang et al. 2015).

As opposed to N-GP and $\mathrm{NH}_{2}-\mathrm{GP}$, little $\mathrm{SMX}(\sim 8 \%)$ was removed within experiments that contained GO and PS after 24 hours (Fig. 2), which suggests that the PS was not activated by GO. Prior work has indicated that with oxygen containing functional groups (e.g. - COOH/$\mathrm{OH}$ ) on the surface of both carbon nanotubes (Lee, Lee et al. 2015) and active carbon (Lee, Lo et al. 2013) can significantly promote PS oxidation. However, addition of the GO used herein, even with abundant oxygen-containing functional groups, did not activate PS under the conditions examined. Moreover, the inability of oxidized graphene materials to activate PS suggests that the promoted SMX oxidation associated with the functionalized graphene-based materials cannot be ascribed only to surface activation of honeycomb-shaped covalent carbon. Additionally, a separate study conducted by Duan et al. (Duan, Sun et al. 2015) showed that graphene materials with high oxygen content (30\%) act poorly as PS activators. 


\subsection{Effects of Initial pH on SMX Removal}

Given the impact of $\mathrm{pH}$ on PS oxidation, $\mathrm{pH}$ variability may promote or inhibit SMX removal (Ahmad, Teel et al. 2013). Thus, experiments were repeated with various initial $\mathrm{pH}$ conditions. Fig. 3 presents the resulting variation of SMX removal rates observed within experimental systems at initial $\mathrm{pH} 3,6$, and 9. For the N-GP with PS system, the SMX removal rate increased with increased $\mathrm{pH}$, and at initial $\mathrm{pH} 9$ the $\mathrm{SMX}$ removal was reached $>99.9 \%$ within $1 / 2$ hour (Fig. 3a). In the N-GP with PS system, the $\mathrm{OH}^{-}$dependent SMX removal rate is

likely related to the $\mathrm{PS}$-activation pathway. $\mathrm{SP}^{2}$ carbon adjacent to the $\mathrm{N}$ atoms was probably the main catalysis site in N-GP, which was less impacted by pH change (Duan, Ao et al. 2015). Moreover, as discussed above, since $\mathrm{OH}^{-}$becomes consumed in PS activation process, the increase of $\mathrm{OH}^{-}$can promote PS activation and SMX decomposition.

For the $\mathrm{NH}_{2}$-GP with PS system, SMX removal had a comparable rate at initial $\mathrm{pH} 3$ and 6. However, SMX decay decreased at initial $\mathrm{pH} 9$ with less than 5\% SMX removal was observed (Fig. 3b). In $\mathrm{NH}_{2}$-GP with PS system, amine functional groups are the main active sites for catalysis. CNT-bound amine functional groups have a $\mathrm{pKa}=8.5$ (Wong, Woolley et al. 1998). Thus, amine groups are neutral at $\mathrm{pH} 9$, and they are protonated and positively charged at $\mathrm{pH} 3$ and 6. This $\mathrm{pH}$-dependent behavior indicates that protonation of amine groups is critical for enhancing the PS catalytic ability of $\mathrm{NH}_{2}$-GP. Additionally, $\mathrm{PS}$ also remained relatively stable at $\mathrm{pH} 9$, which further confirmed the low catalytic efficiency of neutralized amine groups.

In contrast, SMX concentrations remained stable (i.e., $\leqslant 5 \%$ change) in the GO and PS experiments (Fig. 3c) and PS control (Table S3) systems for all three initial pH values tested. 
Increasing initial $\mathrm{pH}$ to 9 and decreasing initial $\mathrm{pH}$ to 3 had negligible impacts on SMX removal in PS control system. These results are similar to observations made by Almad et al. Although $\mathrm{pH}$ activation of $\mathrm{PS}$ does occur, the $\mathrm{pH}$ must be $<\mathrm{pH} 2$ or $>\mathrm{pH} 11$ to have significant activation effect (Ahmad, Teel et al. 2013). Similar to the control system, SMX was stable in the GO with PS system across the examined initial $\mathrm{pH}$ variability range. Due to lack of PS catalytic ability of $\mathrm{GO}$, further study was only carried on for $\mathrm{N}-\mathrm{GP}$ and $\mathrm{NH}_{2}-\mathrm{GP}$.

\subsection{Effects of Ionic Strength on SMX Removal}

Increasing the ionic strength will reduce the zeta potential of particles through compressing the thickness of the electric double layer, which can impact solute and graphenebased particle interactions. This is generally more influential for outer-sphere interactions (i.e., electrostatic bonding) compared to inner-sphere complexation (i.e., covalent bonding or a combination of covalent and ionic bonding) (Thiel and Madey 1987). Fig. 4a-1 \& 4b-1 present the ionic strength control experiment results (i.e., in DI water) for SMX sorption and total removal. SMX sorption was measurable for both $\mathrm{N}-\mathrm{GP}$ and $\mathrm{NH}_{2}-\mathrm{GP}$. SMX sorption to $\mathrm{NH}_{2}-\mathrm{GP}$ was $\sim 10-20 \%$, which was less than the $40 \%$ SMX sorption to N-GP. Increasing ionic strength to $100 \mathrm{mM}$ (with addition of $\mathrm{NaCl}$ or $\mathrm{Na}_{2} \mathrm{SO}_{4}$ ) had a negligible effect on SMX sorption and degradation within N-GP and PS (Fig. 4a-2 \& 4a-3) or $\mathrm{NH}_{2}-\mathrm{GP}$ and PS (Fig. 4b-2 and 4b-3), which suggests that the interactions are generated mainly through inner-sphere interaction among SMX, PS, and N-GP or $\mathrm{NH}_{2}$-GP surface catalysis sites. 
It has been shown that chloride ions can be oxidized by sulfate radical to $\mathrm{Cl} \bullet\left(\mathrm{k}_{\mathrm{SO} 4 \bullet^{-}}=2.0\right.$ $\times 10^{8} \mathrm{M}^{-1} \mathrm{~s}^{-1}$ ), which rapidly combines with another chloride in water forming $\mathrm{Cl}_{2} \bullet^{-}$(chlorine radical) (Anipsitakis, Dionysiou et al. 2006). The potential of the chlorine radical $\left(\mathrm{E}^{0} \mathrm{Cl}_{2} \cdot{ }^{-} / 2 \mathrm{Cl}^{-}=\right.$ $2.09 \mathrm{~V})$ is lower than sulfate radical $\left(\mathrm{E}^{\mathrm{o}} \mathrm{SO}^{-} \cdot^{-} / \mathrm{SO} 42-=2.5-3.1 \mathrm{~V}\right)$. Depending on the target pollutant, the formation of chlorine radicals may impede or improve the pollutant degradation rate during sulfate radical oxidation (Zhang, Zhu et al. 2013, Zhang, Chen et al. 2014). The results of increasing chloride concentration are shown in Fig. 4, which indicates that the presence of $100 \mathrm{mM}$ of chloride has a negligible effect on the SMX removal rate relative to the DI water control. This indicates that chloride ions did not interfere with the SMX oxidation process in both the N-GP with PS and $\mathrm{NH}_{2}$-GP with PS systems. Similarly, $\mathrm{Na}_{2} \mathrm{SO}_{4}$ had no measureable effect on SMX sorption or degradation either. Overall, the inability of ionic strength and chloride content variations to inhibit, or even alter, PS activation and SMX oxidation in both N-GP with PS and $\mathrm{NH}_{2}$-GP with PS systems likely suggests that the reactions are dominated by the particlesurface interaction or non-radical reactions.

\subsection{Effects of Ethanol on SMX Removal}

During PS catalysis, sulfate and hydroxyl radicals are often considered as reactive species for contaminant oxidation (Anipsitakis and Dionysiou 2004, Yan, Lei et al. 2011, Lei, Zhang et al. 2015). Given the rapid reaction rate of ethanol with both sulfate and hydroxyl radicals $(\mathrm{k} \cdot \mathrm{OH}=$ $\left.(1.2-2.8) \times 10^{9} \mathrm{M}^{-1} \mathrm{~s}^{-1} ; \mathrm{k}_{\mathrm{SO} 40^{-}}=(1.6-7.8) \times 10^{7} \mathrm{M}^{-1} \mathrm{~s}^{-1}\right)$, when radicals are the primary oxidation species, the presence of ethanol in excess can significantly reduce PS oxidation efficiency 
through radical scavenging (Anipsitakis and Dionysiou 2003, Lei, Zhang et al. 2015). Thus, ethanol addition was used to investigate the role of sulfate and hydroxyl radicals in SMX degradation.

Even though a relatively large amount was added (molar ratio ethanol:PS=500:1), ethanol had a negligible effect on SMX sorption and total removal in both $\mathrm{N}-\mathrm{GP}$ with PS and $\mathrm{NH}_{2}-\mathrm{GP}$ with PS systems (Fig. 5a-1 \& 5b-1). These results indicated that SMX oxidation in N-GP with PS and $\mathrm{NH}_{2}-\mathrm{GP}$ with PS systems did not follow the conventional PS-activation mechanism (Tsitonaki, Petri et al. 2010). Lack of quenching efficiency of ethanol during heterogeneous PS activation also has been observed by Zhang et al. when copper oxides were applied as activators (Zhang, Chen et al. 2014). Two possible explanations have been proposed to explain PS activation recently: 1) the activation system does not follow the radical generation mechanism (Zhang, Chen et al. 2014), and 2) radical generation mainly occurs at the solid-particle surface, and the ability of ethanol to access these active reaction sites at the graphene/aqueous interface is limited.

\subsection{Effects of $\mathrm{NaHCO}_{3}$ on SMX Removal}

As generally ubiquitous aqueous ions (Stiff 1971), bicarbonate can also inhibit oxidation as a radical quencher (Zhou, Song et al. 2013). Thus, the effect of bicarbonate additions on SMX overall removal in $\mathrm{N}-\mathrm{GP}$ with PS or $\mathrm{NH}_{2}-\mathrm{GP}$ with PS system was investigated, and the results are shown in Fig. 5a-2 \& 5b-2. In the N-GP with PS system, with $100 \mathrm{mM}$ bicarbonate, the SMX sorption slightly decreased indicating the occurrence of sorption competition between SMX and 
bicarbonate (Fig. 5a-2). However, the SMX removal rate remained similar to the rate observed within the DI water without the bicarbonate addition. This provides additional evidence of the significant potential for N-GP with PS to catalyze PS activation and pollution removal over a wide range of aquatic chemistries. In contrast, SMX removal within the $\mathrm{NH}_{2}-\mathrm{GP}$ with PS system became significantly impeded upon addition of $100 \mathrm{mM}$ bicarbonate (Fig. 5b-2). The inhibition of SMX removal, and enhanced PS stability, indicated that the catalytic ability of $\mathrm{NH}_{2}-\mathrm{GP}$ was suppressed. The decreased catalysis effect of $\mathrm{NH}_{2}$-GP was likely due to complexation between bicarbonate and amine functional groups (Sivadas, Vijayalakshmi et al. 2013), which inhibited the ability of $\mathrm{NH}_{2}$ to activate PS.

\subsection{Effects of Humic Acid on SMX Removal}

Humic acid (HA), a major component of natural organic matter, is ubiquitous in the environment. Due to the redox properties of HA, oxidant consumption may be impacted by HA occurrence, as well (Struyk and Sposito 2001). Thus, the effect of HA additions on SMX removal was examined within the N-GP with PS and $\mathrm{NH}_{2}-\mathrm{GP}$ with PS systems, and as expected, presence of HA decreased SMX overall removal. In 3 hours, SMX removals with HA were only $33 \%$ and $5 \%$ in N-GP with PS and $\mathrm{NH}_{2}$-GP with PS system, respectively (Fig. 5a-3 \& 5b-3). With HA, SMX sorption to $\mathrm{NH}_{2}$-GP was also reduced (Fig. 5b-3), which indicated competitive sorption between HA and SMX. The reduced SMX removal efficiency was likely due to the competition between HA and SMX for both sorption sites, which reduced SMX sorption and its proximity to PS activation reactive sites. Alternatively, in the N-GP with PS system when the 
HA concentration was as high as $250 \mathrm{mg} \mathrm{L}^{-1}, 30 \%$ SMX was still removed (as noted above) within 1 hour (Fig. 5a-3). That suggests that the inhibition effect of HA would be limited since HA concentrations are usually less than $50 \mathrm{mg} \mathrm{L}^{-1}$ in aqueous environments (Redman, Macalady et al. 2002). These results were in agreement of previous investigators (Lee, Lee et al. 2015) who observed, during oxidation of PS activated CNT, $10 \mathrm{mg} \mathrm{L}^{-1}$ of HA only inhibited pollution removal by $10-20 \%$.

\section{CONCLUSIONS}

This work demonstrated for the first time that both $\mathrm{N}-\mathrm{GP}$ and $\mathrm{NH}_{2}-\mathrm{GP}$ effectively activate PS and sorb SMX, which resulted in enhanced SMX overall removal through coupled sorption and oxidative transformation. Reactions were relatively rapid, which was likely enhanced by the coupling of contaminant sorption and surface-based PS activation providing both removal and treatment at the graphene surface. This reveals a great potential application for graphene-based materials with heteroatom-doping functionalization as a more environmentallyfriendly and metal-free PS catalyst for pollutant oxidation, which may have applications in water and waste-water treatment, as well as, subsurface (in situ) chemical oxidation. Compared to other PS activation methods (e.g., toxic metal-based, heat, or base) that require reagent or energy inputs to continue throughout treatment time periods, graphene-based activation is a promising metal-free alternative, which is a non-toxic PS catalytic process requiring no additional chemical or energy inputs. 
The activation ability of $\mathrm{NH}_{2}$-GP can be limited under some aquatic chemistry conditions including occurrence of high $\mathrm{pH}$ and presence of HA and bicarbonate ions. Interestingly though, the N-GP system was less affected by solution chemistry impacts, compared to the $\mathrm{NH}_{2}-\mathrm{GP}$ system, making it more widely applicable for PS activation. The lack of influence of solution chemistry over PS activation, and SMX removal, within the N-GP system is additionally beneficial to prevent undesired reactions with background aqueous compounds. However, these results also suggest that the conventional PS activation mechanism and the explicit electrontransfer pathway for SMX oxidation in the N-GP and PS system and the $\mathrm{NH}_{2}-\mathrm{GP}$ and PS system still requires additional investigation. Due to the complex nature of the carbon structure combined with heteroatom-doping functionalization, further studies are needed to examine the mechanisms of PS activation catalyzed by heteroatom doping of graphene-based materials.

\section{Acknowledgements}

This research was supported by the US Department of Defense Strategic Environmental Research and Development Program (ER-2302) and the Plant \& Environmental Science Department at NMSU. We also appreciate the support of Omar Holguin, Barry Dungan, Barbara Hunter, Mark Brusseau, and other members of the Carroll Lab.

\section{Appendix A. Supplementary Data}

Supplementary data related to this article can be found online. 


\section{References}

2. Ahmad, M., A. L. Teel and R. J. Watts (2013). "Mechanism of Persulfate Activation by Phenols." Environmental Science \& Technology 47(11): 5864-5871.

3. Ahn, S., T. D. Peterson, J. Righter, D. M. Miles and P. G. Tratnyek (2013). "Disinfection of Ballast Water with Iron Activated Persulfate." Environmental Science \& Technology 47(20): 11717-11725.

4. Anipsitakis, G. P. and D. D. Dionysiou (2003). "Degradation of Organic Contaminants in Water with Sulfate Radicals Generated by the Conjunction of Peroxymonosulfate with Cobalt." Environmental Science \& Technology 37(20): 4790-4797.

5. Anipsitakis, G. P. and D. D. Dionysiou (2004). "Radical Generation by the Interaction of Transition Metals with Common Oxidants." Environmental Science \& Technology 38(13): 3705-3712.

6. Anipsitakis, G. P., D. D. Dionysiou and M. A. Gonzalez (2006). "Cobalt-Mediated Activation of Peroxymonosulfate and Sulfate Radical Attack on Phenolic Compounds. Implications of Chloride Ions." Environmental Science \& Technology 40(3): 1000-1007.

7. Baran, W., E. Adamek, J. Ziemiańska and A. Sobczak (2011). "Effects of the presence of sulfonamides in the environment and their influence on human health." Journal of Hazardous Materials 196: 1-15.

8. Barnes, K. K., S. C. Christenson, D. W. Kolpin, M. J. Focazio, E. T. Furlong, S. D. Zaugg, M. T. Meyer and L. B. Barber (2004). "Pharmaceuticals and Other Organic Waste Water Contaminants Within a Leachate Plume Downgradient of a Municipal Landfill." Ground Water Monitoring \& Remediation 24(2): 119-126. 
9. Cai, C., H. Zhang, X. Zhong and L. Hou (2014). "Electrochemical enhanced heterogeneous activation of peroxydisulfate by $\mathrm{Fe}-\mathrm{Co} / \mathrm{SBA}-15$ catalyst for the degradation of Orange II in water." Water Research 66: 473-485.

10. Chaplin, B. P. (2014). "Critical review of electrochemical advanced oxidation processes for water treatment applications." Environmental Science: Processes \& Impacts 16(6): $1182-1203$.

11. Cuypers, C., T. Grotenhuis, J. Joziasse and W. Rulkens (2000). "Rapid persulfate oxidation predicts PAH bioavailability in soils and sediments." Environmental Science \& Technology 34(10): 2057-2063.

12. Drzewicz, P., L. Perez-Estrada, A. Alpatova, J. W. Martin and M. Gamal El-Din (2012). "Impact of Peroxydisulfate in the Presence of Zero Valent Iron on the Oxidation of Cyclohexanoic Acid and Naphthenic Acids from Oil Sands Process-Affected Water." Environmental Science \& Technology 46(16): 8984-8991.

13. Duan, X., Z. Ao, H. Sun, S. Indrawirawan, Y. Wang, J. Kang, F. Liang, Z. H. Zhu and S. Wang (2015). "Nitrogen-Doped Graphene for Generation and Evolution of Reactive Radicals by Metal-Free Catalysis." ACS Applied Materials \& Interfaces 7(7): 4169-4178.

14. Duan, X. G., H. Q. Sun, J. Kang, Y. X. Wang, S. Indrawirawan and S. B. Wang (2015). "Insights into Heterogeneous Catalysis of Persulfate Activation on DimensionalStructured Nanocarbons." Acs Catalysis 5(8): 4629-4636.

15. Fang, G., J. Gao, D. D. Dionysiou, C. Liu and D. Zhou (2013). "Activation of Persulfate by Quinones: Free Radical Reactions and Implication for the Degradation of PCBs." Environmental Science \& Technology 47(9): 4605-4611. 
16. Furman, O. S., A. L. Teel and R. J. Watts (2010). "Mechanism of Base Activation of Persulfate." Environmental Science \& Technology 44(16): 6423-6428.

17. Hussain, H., I. R. Green and I. Ahmed (2013). "Journey Describing Applications of Oxone in Synthetic Chemistry." Chemical Reviews 113(5): 3329-3371.

18. Jiang, Y. H., J. B. Zhang, B. D. Xi, D. An, Y. Yang and M. X. Li (2015). "Degradation of toluene-2,4-diamine by persulphate: kinetics, intermediates and degradation pathway." Environmental Technology 36(11): 1441-1447.

19. Kolthoff, I. M. and I. K. Miller (1951). "The Chemistry of Persulfate. I. The Kinetics and Mechanism of the Decomposition of the Persulfate Ion in Aqueous Medium1." Journal of the American Chemical Society 73(7): 3055-3059.

20. Kronholm, J., H. Metsälä, K. Hartonen and M.-L. Riekkola (2001). "Oxidation of 4Chloro-3-methylphenol in Pressurized Hot Water/Supercritical Water with Potassium Persulfate as Oxidant." Environmental Science \& Technology 35(15): 3247-3251.

21. Kuila, T., S. Bose, A. K. Mishra, P. Khanra, N. H. Kim and J. H. Lee (2012). "Chemical functionalization of graphene and its applications." Progress in Materials Science 57(7): 1061-1105.

22. Lee, E., S. Lee, J. Park, Y. Kim and J. Cho (2013). "Removal and transformation of pharmaceuticals in wastewater treatment plants and constructed wetlands." Drink. Water Eng. Sci. 6(2): 89-98.

23. Lee, H., H.-J. Lee, J. Jeong, J. Lee, N.-B. Park and C. Lee (2015). "Activation of persulfates by carbon nanotubes: Oxidation of organic compounds by nonradical mechanism." Chemical Engineering Journal 266: 28-33. 
24. Lee, Y.-C., S.-L. Lo, J. Kuo and C.-P. Huang (2013). "Promoted degradation of perfluorooctanic acid by persulfate when adding activated carbon." Journal of Hazardous Materials 261: 463-469.

25. Lei, Y., H. Zhang, J. W. Wang and J. Ai (2015). "Rapid and continuous oxidation of organic contaminants with ascorbic acid and a modified ferric/persulfate system." Chemical Engineering Journal 270: 73-79.

26. Liang, C. J., C. F. Huang, N. Mohanty and R. M. Kurakalva (2008). "A rapid spectrophotometric determination of persulfate anion in ISCO." Chemosphere 73(9): 1540-1543.

27. Redman, A. D., D. L. Macalady and D. Ahmann (2002). "Natural Organic Matter Affects Arsenic Speciation and Sorption onto Hematite." Environmental Science \& Technology 36(13): 2889-2896.

28. Sepulveda, P. and J. G. P. Binner (2001). "Persulfate-amine initiation systems for gelcasting of ceramic foams." Chemistry of Materials 13(11): 4065-4070.

29. Sivadas, D. L., K. P. Vijayalakshmi, R. Rajeev, K. Prabhakaran and K. N. Ninan (2013). "Supramolecular beta-cyclodextrin-aniline system: a new class of amine on solid support for carbon dioxide capture with high amine efficiency." Rsc Advances 3(46): 2404124045 .

30. Stiff, M. J. (1971). "Copper/bicarbonate equilibria in solutions of bicarbonate ion at concentrations similar to those found in natural water." Water Research 5(5): 171-176.

31. Struyk, Z. and G. Sposito (2001). "Redox properties of standard humic acids." Geoderma 102(3-4): 329-346. 
32. Sun, H., S. Liu, G. Zhou, H. M. Ang, M. O. Tadé and S. Wang (2012). "Reduced Graphene Oxide for Catalytic Oxidation of Aqueous Organic Pollutants." ACS Applied Materials \& Interfaces 4(10): 5466-5471.

33. Sun, H., Y. Wang, S. Liu, L. Ge, L. Wang, Z. Zhu and S. Wang (2013). "Facile synthesis of nitrogen doped reduced graphene oxide as a superior metal-free catalyst for oxidation." Chemical Communications 49(85): 9914-9916.

34. Thiel, P. A. and T. E. Madey (1987). "The interaction of water with solid surfaces: Fundamental aspects." Surface Science Reports 7(6-8): 211-385.

35. Thiele-Bruhn, S. (2003). "Pharmaceutical antibiotic compounds in soils - a review." Journal of Plant Nutrition and Soil Science-Zeitschrift Fur Pflanzenernahrung Und Bodenkunde 166(2): 145-167.

36. Tsitonaki, A., B. Petri, M. Crimi, H. Mosbaek, R. L. Siegrist and P. L. Bjerg (2010). "In Situ Chemical Oxidation of Contaminated Soil and Groundwater Using Persulfate: A Review." Critical Reviews in Environmental Science and Technology 40(1): 55-91.

37. Wang, H., T. Maiyalagan and X. Wang (2012). "Review on Recent Progress in NitrogenDoped Graphene: Synthesis, Characterization, and Its Potential Applications." $\underline{\text { ACS }}$ Catalysis 2(5): 781-794.

38. Wang, X., Y. Qin, L. Zhu and H. Tang (2015). "Nitrogen-Doped Reduced Graphene Oxide as a Bifunctional Material for Removing Bisphenols: Synergistic Effect between Adsorption and Catalysis." Environmental Science \& Technology 49(11): 6855-6864. 
39. Watts, R. J. and A. L. Teel (2006). "Treatment of Contaminated Soils and Groundwater Using ISCO." Practice Periodical of Hazardous, Toxic, and Radioactive Waste Management 10(1): 2-9.

40. Wong, S. S., A. T. Woolley, E. Joselevich, C. L. Cheung and C. M. Lieber (1998). "Covalently-functionalized single-walled carbon nanotube probe tips for chemical force microscopy." Journal of the American Chemical Society 120(33): 8557-8558.

41. Yan, J., M. Lei, L. Zhu, M. N. Anjum, J. Zou and H. Tang (2011). "Degradation of sulfamonomethoxine with $\mathrm{Fe} 3 \mathrm{O} 4$ magnetic nanoparticles as heterogeneous activator of persulfate." Journal of Hazardous Materials 186(2-3): 1398-1404.

42. Yang, Y., J. J. Pignatello, J. Ma and W. A. Mitch (2014). "Comparison of Halide Impacts on the Efficiency of Contaminant Degradation by Sulfate and Hydroxyl Radical-Based Advanced Oxidation Processes (AOPs)." Environmental Science \& Technology 48(4): 2344-2351.

43. Zhang, T., Y. Chen, Y. Wang, J. Le Roux, Y. Yang and J.-P. Croué (2014). "Efficient Peroxydisulfate Activation Process Not Relying on Sulfate Radical Generation for Water Pollutant Degradation." Environmental Science \& Technology 48(10): 5868-5875.

44. Zhang, T., H. Zhu and J.-P. Croué (2013). "Production of Sulfate Radical from Peroxymonosulfate Induced by a Magnetically Separable CuFe2O4 Spinel in Water: Efficiency, Stability, and Mechanism." Environmental Science \& Technology 47(6): 2784-2791. 
45. Zhao, Y., R. Nakamura, K. Kamiya, S. Nakanishi and K. Hashimoto (2013). "Nitrogendoped carbon nanomaterials as non-metal electrocatalysts for water oxidation." Nat Commun 4.

46. Zhong, H., M. L. Brusseau, Y. K. Wang, N. Yan, L. Quig and G. R. Johnson (2015). "Insitu activation of persulfate by iron filings and degradation of 1,4-dioxane." Water Research 83: 104-111.

47. Zhou, L., W. Song, Z. Chen and G. Yin (2013). "Degradation of Organic Pollutants in Wastewater by Bicarbonate-Activated Hydrogen Peroxide with a Supported Cobalt Catalyst." Environmental Science \& Technology 47(8): 3833-3839. 


\section{Figure Captions:}

Fig. 1. Normalized concentration versus time trend of initially $1 \mathrm{mM}$ persulfate (PS) concentration in nitrogen-doped graphene (N-GP), aminated graphene $\left(\mathrm{NH}_{2}-\mathrm{GP}\right)$, and graphene oxide (GO) suspensions (initial pH 6). All graphene suspensions were maintained at $50 \mathrm{mg} \mathrm{L}^{-1}$, and error bars represent standard deviations.

Fig. 2. Normalized concentration versus time trend of sulfamethoxazole (SMX) (initially $5 \mathrm{mg} \mathrm{L}^{-}$ ${ }^{1}$ ) concentration with $\mathrm{PS}$ in $\mathrm{N}-\mathrm{GP}, \mathrm{NH}_{2}-\mathrm{GP}$, and $\mathrm{GO}$ suspensions (initial $\mathrm{pH}$ 6). All graphene suspensions were $50 \mathrm{mg} \mathrm{L}^{-1}$, and error bars represent standard deviations.

Fig. 3. Effect of solution chemistry ( $\mathrm{pH}$ variability) on SMX (initially $5 \mathrm{mg} \mathrm{L}^{-1}$ ) removal kinetics by $1 \mathrm{mM}$ PS in (a) N-GP, (b) $\mathrm{NH}_{2}-\mathrm{GP}$, and (c) GO suspensions. All graphene suspensions were $50 \mathrm{mg} \mathrm{L}^{-1}$, and error bars represent standard deviations.

Fig. 4. Effect of solution chemistry (ion type and strength) on SMX (initially $5 \mathrm{mg} \mathrm{L}^{-1}$ ) removal kinetics by 1 mM PS in N-GP [(a-1) DI water control; (a-2) $100 \mathrm{mM} \mathrm{NaCl}$; (a-3) $100 \mathrm{mM}$ $\mathrm{Na}_{2} \mathrm{SO}_{4}$ all in N-GP] and $\mathrm{NH}_{2}$-GP [(b-1) DI water control; (b-2) $100 \mathrm{mM} \mathrm{NaCl}$; (b-3) $100 \mathrm{mM}$ $\mathrm{Na}_{2} \mathrm{SO}_{4}$ all in $\mathrm{NH}_{2}-\mathrm{GP}$ ] suspensions (sorption experiments were without PS). All graphene suspensions were $50 \mathrm{mg} \mathrm{L}^{-1}$, and error bars represent standard deviations.

Fig. 5. Effect of oxidant consumers $\left(500 \mathrm{mM}\right.$ ethanol, $100 \mathrm{mM}$ bicarbonate, $250 \mathrm{mg} \mathrm{L}^{-1}$ humic acid) on SMX (initially $5 \mathrm{mg} \mathrm{L}^{-1}$ ) removal kinetics by $1 \mathrm{mM}$ PS in N-GP [(a-1) ethanol; (a-2) bicarbonate; (a-3) humic acid all in N-GP] and $\mathrm{NH}_{2}$-GP [(b-1) ethanol; (b-2) bicarbonate; (b-3) 
humic acid all in $\mathrm{NH}_{2}-\mathrm{GP}$ ] suspensions (sorption experiments were without PS). All graphene suspensions were $50 \mathrm{mg} \mathrm{L}^{-1}$, and error bars represent standard deviations.

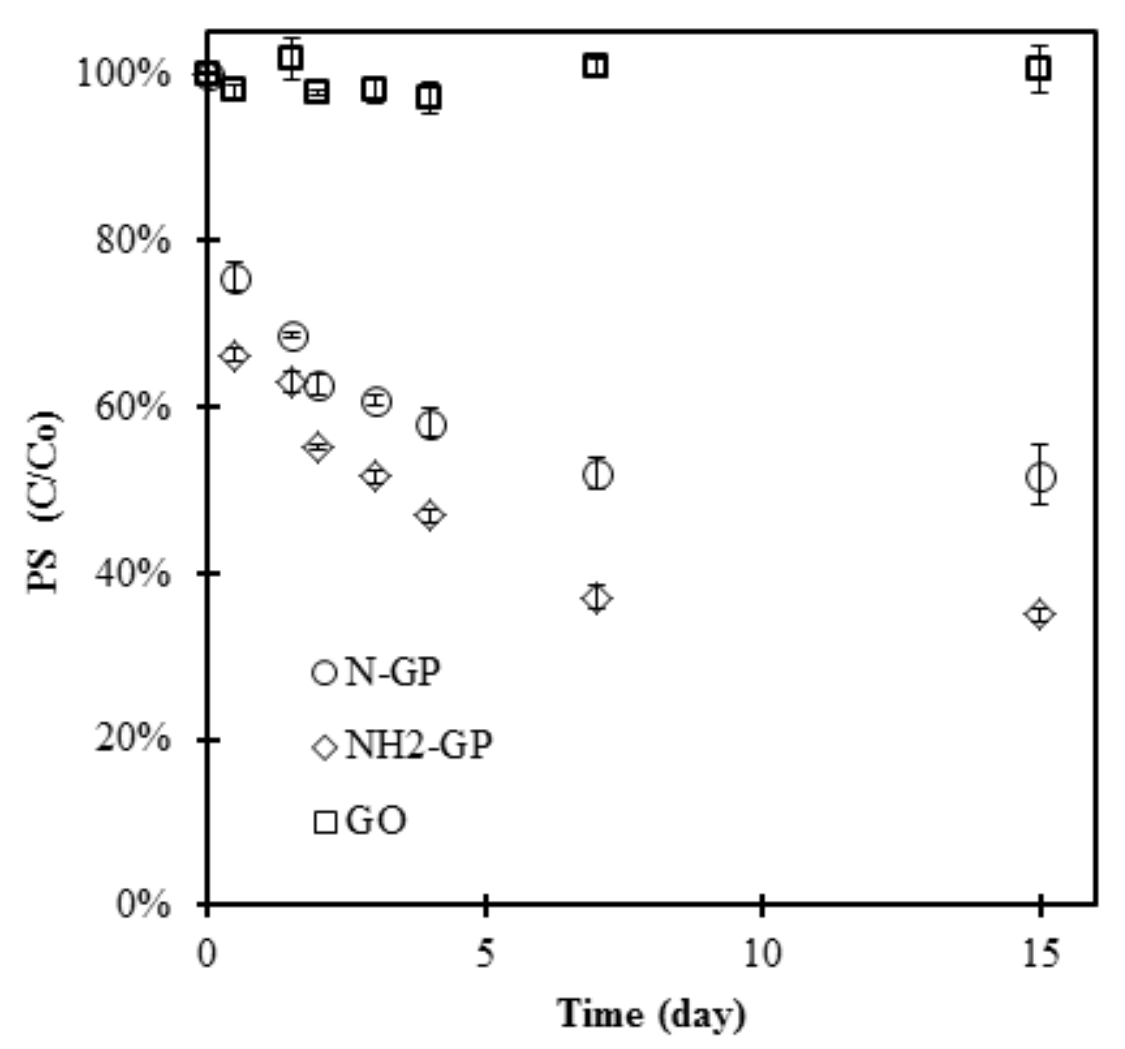

Fig. 1. Normalized concentration versus time trend of initially $1 \mathrm{mM}$ persulfate (PS) concentration in nitrogen-doped graphene (N-GP), aminated graphene $\left(\mathrm{NH}_{2}-\mathrm{GP}\right)$, and graphene oxide (GO) suspensions (initial pH 6). All graphene suspensions were maintained at $50 \mathrm{mg} \mathrm{L}^{-1}$, and error bars represent standard deviations. 


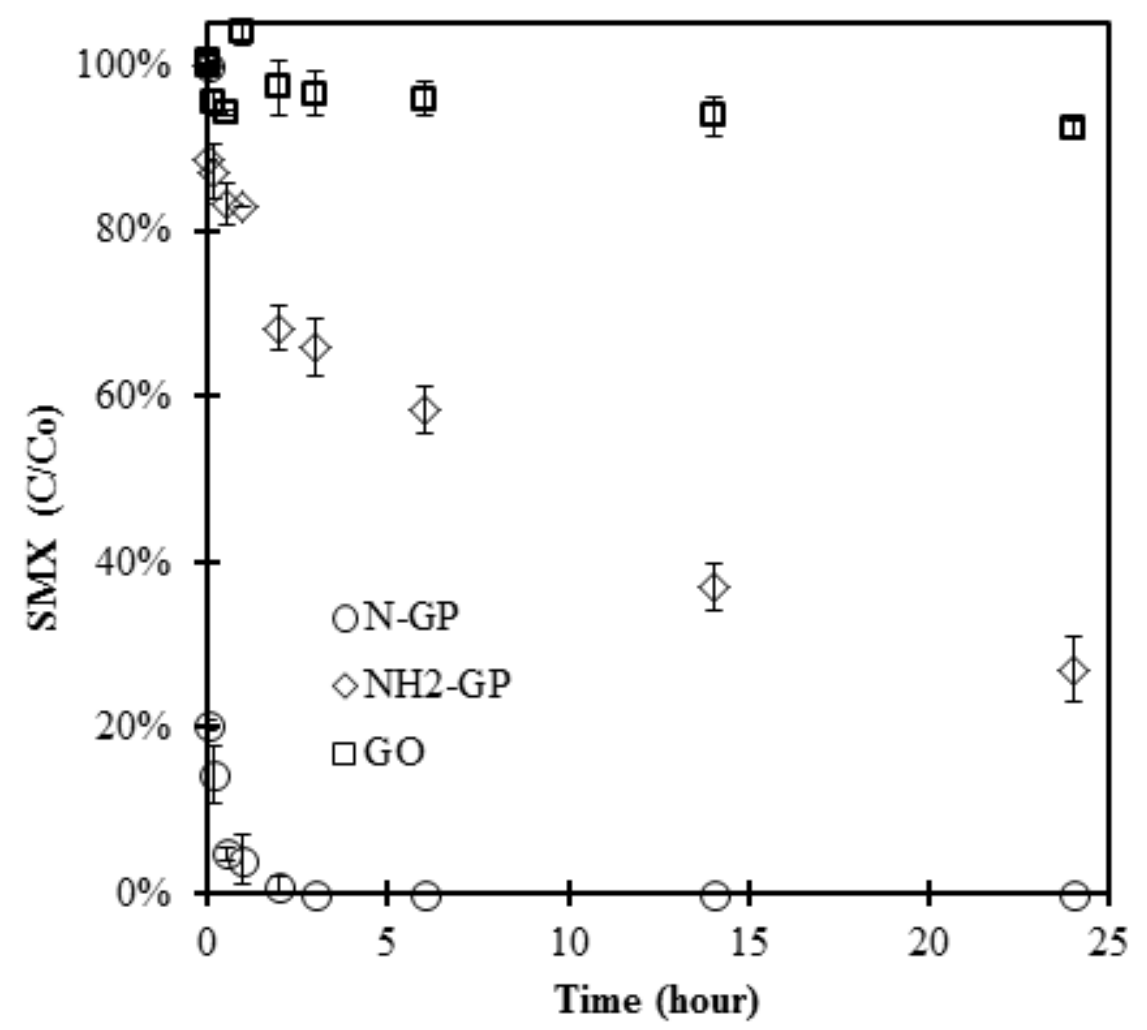

Fig. 2. Normalized concentration versus time trend of sulfamethoxazole (SMX) (initially $5 \mathrm{mg} \mathrm{L}^{-}$ ${ }^{1}$ ) concentration with PS in $\mathrm{N}-\mathrm{GP}, \mathrm{NH}_{2}-\mathrm{GP}$, and $\mathrm{GO}$ suspensions (initial $\mathrm{pH}$ 6). All graphene suspensions were $50 \mathrm{mg} \mathrm{L}^{-1}$, and error bars represent standard deviations. 

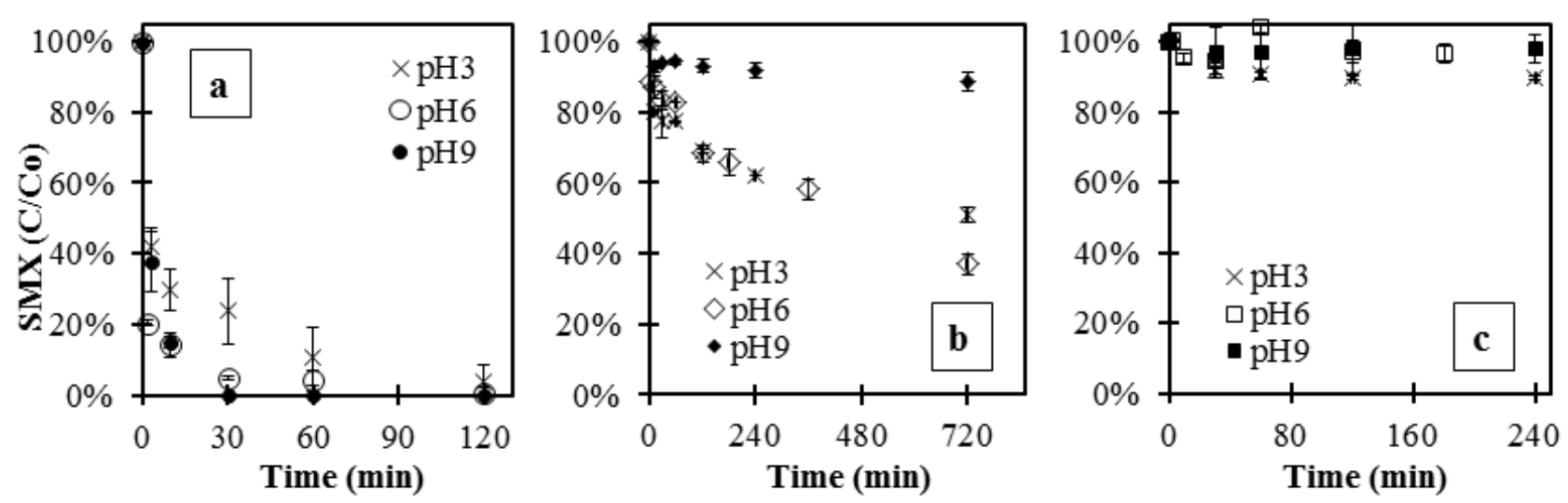

Fig. 3. Effect of solution chemistry (pH variability) on SMX (initially $5 \mathrm{mg} \mathrm{L}^{-1}$ ) removal kinetics by $1 \mathrm{mM}$ PS in (a) N-GP, (b) $\mathrm{NH}_{2}-\mathrm{GP}$, and (c) GO suspensions. All graphene suspensions were $50 \mathrm{mg} \mathrm{L}^{-1}$, and error bars represent standard deviations.
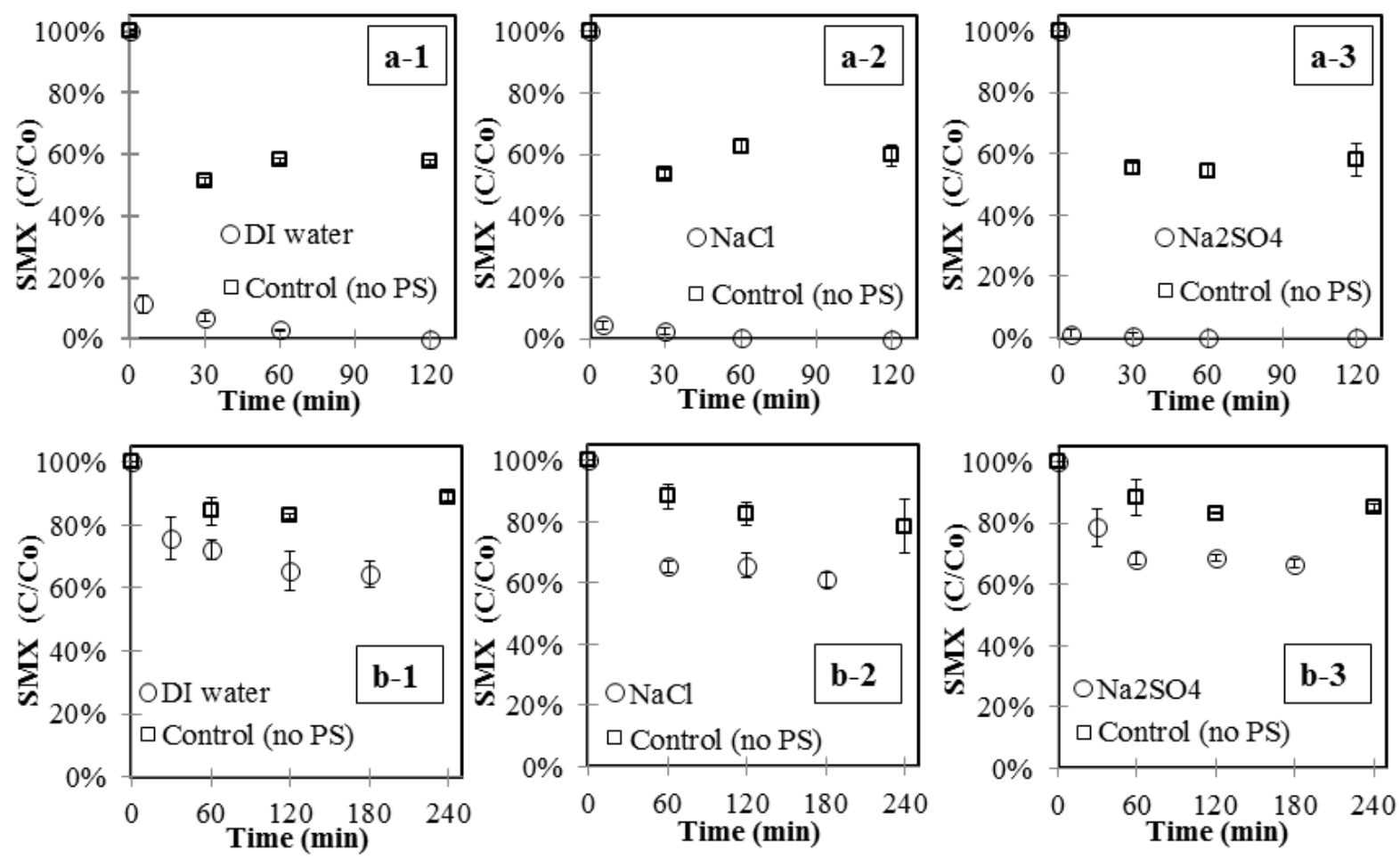

Fig. 4. Effect of solution chemistry (ion type and strength) on SMX (initially $5 \mathrm{mg} \mathrm{L}^{-1}$ ) removal kinetics by 1 mM PS in N-GP [(a-1) DI water control; (a-2) $100 \mathrm{mM} \mathrm{NaCl}$; (a-3) $100 \mathrm{mM}$ 
$\mathrm{Na}_{2} \mathrm{SO}_{4}$ all in N-GP] and $\mathrm{NH}_{2}$-GP [(b-1) DI water control; (b-2) $100 \mathrm{mM} \mathrm{NaCl}$; (b-3) $100 \mathrm{mM}$ $\mathrm{Na}_{2} \mathrm{SO}_{4}$ all in $\left.\mathrm{NH}_{2}-\mathrm{GP}\right]$ suspensions (sorption experiments were without PS). All graphene suspensions were $50 \mathrm{mg} \mathrm{L}^{-1}$, and error bars represent standard deviations.
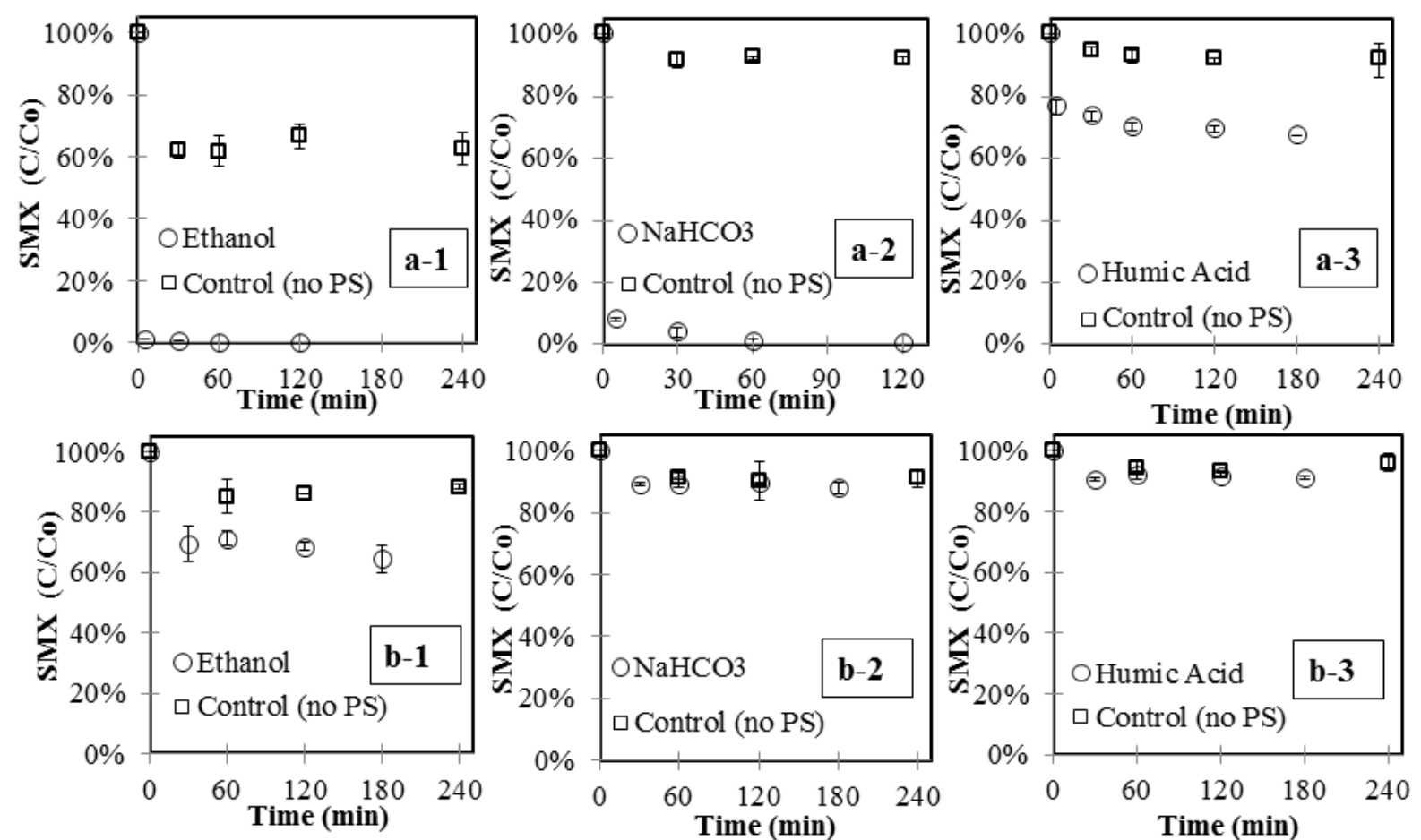

Fig. 5. Effect of oxidant consumers (500 mM ethanol, $100 \mathrm{mM}$ bicarbonate, $250 \mathrm{mg} \mathrm{L}^{-1}$ humic acid) on SMX (initially $5 \mathrm{mg} \mathrm{L}^{-1}$ ) removal kinetics by $1 \mathrm{mM}$ PS in N-GP [(a-1) ethanol; (a-2) bicarbonate; (a-3) humic acid all in N-GP] and $\mathrm{NH}_{2}$-GP [(b-1) ethanol; (b-2) bicarbonate; (b-3) humic acid all in $\mathrm{NH}_{2}$-GP] suspensions (sorption experiments were without PS). All graphene suspensions were $50 \mathrm{mg} \mathrm{L}^{-1}$, and error bars represent standard deviations. 